\title{
AVALIAÇÃo MECÂNICA DE TERMINAIS E BARRAS DE DIREÇÃO DE ACORDO COM A NORMA ABNT NBR 16130
}

\author{
Felipe Rollo $^{1}$, Celso R. Ribeiro ${ }^{1}$ \\ SGS Labmat ${ }^{1}$ \\ E-mails: felipe.rollo@sgs.com, celso.ribeiro@sgs.com
}

\section{RESUMO}

O trabalho apresenta os resultados de um estudo de caso em ensaios mecânicos de terminais e barras de direção realizados de acordo com a norma ABNT NBR 16130, segundo as especificações da Portaria do Inmetro $\mathrm{n}^{0} 247$ de 2013. As características técnicas dos ensaios de torção do conjunto de terminais, arrancamento do pino esférico, folgas axial e radial e ensaios metalúrgicos são apresentados. Os resultados apresentados são exemplos de técnicas de avaliação que são empregadas na avaliação desses produtos e representam parte de um estudo bem mais completo. Os resultados encontrados mostram que o produto avaliado atende à portaria do Inmetro e norma indicada. No entanto, atenção deve ser dada principalmente à realização dos ensaios mecânicos durante a preparação dos corpos de prova.

\section{INTRODUÇÃO}

A Portaria n. ${ }^{\circ}$ 247, de 03 de maio de 2013 em seu artigo primeiro aprovou o Regulamento Técnico da Qualidade para Terminais de Direção, Barras de Direção, Barras de Ligação e Terminais Axiais. O objetivo dessa portaria foi o de estabelecer os requisitos técnicos que devem ser atendidos no Programa de Avaliação da Conformidade para terminais de direção, barras de direção, barras de ligação e terminais axiais, utilizados em veículos rodoviários automotores, principalmente com foco na segurança, visando à prevenção de acidentes. Os componentes cobertos por essa portaria são aplicados em automóveis, camionetas, caminhonetes, veículos comerciais leves, caminhões, caminhões-tratores, ônibus e microônibus. A classificação da capacidade de carga e classificação desses veículos é descrita na norma ABNT NBR 16130 [1].

Para a avaliação dos terminais e barras de direção, barras de ligação e terminais axiais, a partir de ensaios mecânicos e metalúrgicos, devem ser realizados os procedimentos da Portaria n. $^{\circ}$ 247, de 03 de maio de 2013, que são baseados na norma ABNT NBR 16130, que trata dos requisitos e métodos de ensaio aplicados a veículos categorias $\mathrm{M}$ e $\mathrm{N}$ e categorias $\mathrm{G}$ e $\mathrm{O}$. Esses ensaios compreendem: Acabamento Superficial, Acoplamento Cônico, Deflexão à Força, Elasticidade Axial, Elasticidade do Pino Esférico, Ensaio de Impacto no Pino Esférico; Integridade do Material; Resistência ao Arrancamento; Torque de Rotação do Pino Esférico; Torque Angular do Terminal Axial e Torque de Giro [1, 2].

Para a realização dos ensaios dos terminais e barras de direção, barras de ligação e terminais axiais os componentes são divididos por ensaios específicos, compreendendo os requisitos 
para o componente pino esférico; requisitos mínimos para o componente carcaça do conjunto terminal de direção e barra axial e ensaios estáticos no conjunto montado [2].

As Tabelas 1, 2 e 3 resumem os tipos de ensaio e métodos de avaliação do componente pino esférico, carcaça e Conjunto Terminal de Direção [1].

Tabela 1 - Tipo de ensaio e método de avaliação para o componente pino esférico.

\begin{tabular}{|c|c|}
\hline Tipo de Ensaio & Método de Avaliação \\
\hline Integridade do material, conforme item 6.1.1 do RTQ & $\begin{array}{ll}\text { - } & \text { Análise Metalográfica } \\
\text { - } & \text { Líquido penetrante ou } \\
\text { partículas magnéticas } \\
\text { - } \quad \text { Análise química }\end{array}$ \\
\hline Acabamento superficial, conforme item 6.1.2 do RTQ & Rugosidade \\
\hline Rosca do pino esférico, conforme item 6.1.3 do RTQ & Metalografia \\
\hline $\begin{array}{l}\text { Conformidade do material, conforme item } 6.1 .4 \text { do } \\
\text { RTQ }\end{array}$ & $\begin{array}{ll}- & \text { Análise Metalográfica } \\
\text { - } & \text { Ensaio de Dureza } \\
\end{array}$ \\
\hline Acoplamento cônico, conforme item 6.1.5 do RTQ & Ensaio Visual \\
\hline $\begin{array}{l}\text { Carga de deformação do pino esférico do conjunto } \\
\text { terminal de direção, conforme item 6.1.6 do RTQ }\end{array}$ & $\begin{array}{l}\text { • Ensaio Mecânico de } \\
\text { Compressão }\end{array}$ \\
\hline $\begin{array}{l}\text { Ensaio de impacto do pino esférico do conjunto } \\
\text { terminal de direção, conforme item } 6.1 .7 \text { do RTQ }\end{array}$ & $\begin{array}{l}\text { Ensaio Mecânico de } \\
\text { Impacto }\end{array}$ \\
\hline
\end{tabular}

Tabela 2 - Tipo de ensaio e método de avaliação para o componente carcaça.

\begin{tabular}{|l|ll|}
\hline \multicolumn{1}{|c|}{ Tipo de Ensaio } & Método de Avaliação \\
\hline Integridade do material, conforme item 6.2.1 do RTQ & $\begin{array}{l}\bullet \\
\text { partículas magnéticas }\end{array}$ \\
\hline Rosca da haste da carcaça, conforme item 6.2.2 do RTQ & $\bullet$ & Análise Metalográfica \\
\hline $\begin{array}{l}\text { Conformidade do Material, conforme item 6.2.3 do } \\
\text { RTQ }\end{array}$ & $\bullet$ & Análise Metalográfica \\
\hline *RTQ - Regulamento Técnico da Qualidade (Anexo da Portaria Inmetro $\mathrm{N}^{\circ}$ 247/2013) \\
\hline
\end{tabular}

Tabela 3 - Tipo de ensaio e método de avaliação para o conjunto terminal de direção.

\begin{tabular}{|c|c|}
\hline Tipo de Ensaio & Método de Avaliação \\
\hline $\begin{array}{l}\text { Torque de rotação do pino esférico do conjunto terminal } \\
\text { de direção, conforme item 6.3.1 do RTQ }\end{array}$ & - $\quad$ Ensaio Mecânico de Torção \\
\hline $\begin{array}{l}\text { Elasticidade do pino esférico sob carga do conjunto } \\
\text { terminal de direção, conforme item 6.3.2 do RTQ }\end{array}$ & $\begin{array}{l}\text { - Ensaio Mecânico de Tração } \\
\text { e Compressão }\end{array}$ \\
\hline $\begin{array}{l}\text { Resistência ao arrancamento do pino esférico do } \\
\text { conjunto terminal de direção, conforme item } 6.3 .3 \text { do } \\
\text { RTQ }\end{array}$ & Ensaio Mecânico de Tração \\
\hline $\begin{array}{l}\text { Resistência ao arrancamento e torque de giro de } \\
\text { conjunto fixo/grampeado/soldado, conforme item 6.3.4 } \\
\text { do RTQ }\end{array}$ & $\begin{array}{l}\text { - Ensaio Mecânico de Tração } \\
\text { e Torção }\end{array}$ \\
\hline $\begin{array}{l}\text { Torque angular do terminal axial, conforme item 6.3.5 } \\
\text { do RTQ }\end{array}$ & Ensaio Torção \\
\hline Elasticidade axial do pino esférico sob carga do & Ensaio Mecânico de Tração \\
\hline
\end{tabular}




\begin{tabular}{|l|l|}
\hline terminal axial, conforme item 6.3.6 do RTQ & e Compressão \\
\hline $\begin{array}{l}\text { Resistência ao arrancamento do pino esférico do } \\
\text { terminal axial, conforme item 6.3.7 do RTQ }\end{array}$ & $\bullet \quad$ Ensaio Mecânico de Tração \\
\hline $\begin{array}{l}\text { Deflexão à força do conjunto terminal de direção e } \\
\text { terminal axial, conforme item 6.3.8 do RTQ }\end{array}$ & $\begin{array}{l}\text { Ensaio Mecânico de Tração } \\
\text { e Compressão }\end{array}$ \\
\hline * RTQ - Regulamento Técnico da Qualidade (Anexo da Portaria Inmetro No 247/2013) \\
\hline
\end{tabular}

\section{MATERIAIS E MÉTODOS}

Avaliou-se nesse trabalho um terminal de direção, com pino esférico apresentando diâmetro de $30 \mathrm{~mm}$. Nesse trabalho são apresentados os resultados dos ensaios Metalográficos do pino esférico, Folga Axial e Radial, Arrancamento do pino esférico e Torção. A Figura 1 apresenta a imagem do item avaliado.

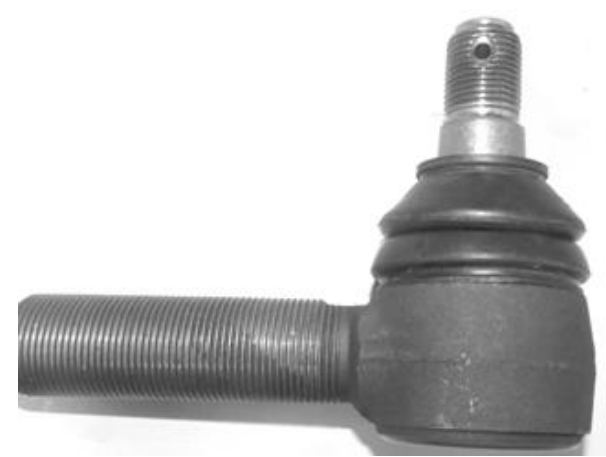

Figura 1 - Terminal de direção avaliado no trabalho

\section{1 - Requisito para o componente pino esférico}

Para essa avaliação o terminal de direção foi desmontado e separado o pino esférico do componente carcaça. A Figura 2 apresenta o componente antes da avaliação.

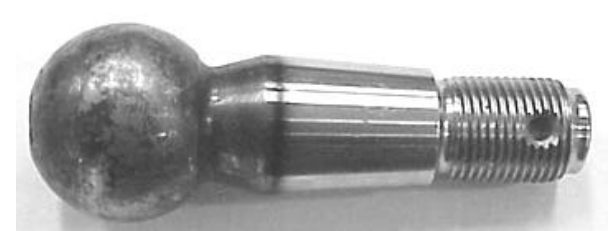

Figura 2 - Pino esférico do Terminal de direção avaliado no trabalho

Para a avaliação da Integridade do Material do pino esférico utilizou-se de técnicas de líquido penetrante; Análise química e Análise metalográfica. As Tabela 4, 5 e 6 resumem os resultados obtidos nos ensaios.

Para a análise por líquido penetrante do pino esférico manteve-se à amostra sob luminosidade de 1800 Lux. O líquido penetrante utilizado foi o Magnaflux Spotcheck (SKL-WP), classificado como Tipo II, Método A, com tempo de penetração de 20 minutos antes da limpeza em água corrente e secagem. A pós a secagem do componente foi aplicado o 
revelador Magnaflux Spotcheck SKD-S2 e aguardou-se 20 minutos para a avaliação do resultado. A Figura 3 apresenta o pino esférico após o ensaio pó líquido penetrante.

Tabela 4 - Resultado obtido no ensaio de líquido penetrante

\begin{tabular}{|c|c|c|c|}
\hline $\begin{array}{c}\text { Característica } \\
\text { Avaliada }\end{array}$ & $\begin{array}{c}\text { Método de } \\
\text { Verificação }\end{array}$ & $\begin{array}{c}\text { Critério de Aceitação } \\
\text { Item 6.1.1 }\end{array}$ & Resultado Obtido \\
\hline $\begin{array}{c}\text { Defeitos } \\
\text { Superfíciais }\end{array}$ & $\begin{array}{c}\text { Analise por } \\
\text { líquido } \\
\text { Penetrante }\end{array}$ & $\begin{array}{c}\text { Não saceitas trincas } \\
\text { internas e externas ou } \\
\text { defeitos superficiais que } \\
\text { levam a formação de } \\
\text { trincas }\end{array}$ & Atende à norma \\
\hline
\end{tabular}

Figura 3 - Pino esférico após o ensaio de líquido penetrante, sem a presença de trincas visíveis.

Para a análise química do pino esférico utilizou-se de Espectrometria de Emissão Óptica por Centelha. A amostra foi cortada e preparada por lixamento até a grana 80 para padronização da superfície. O resultado da análise química foi comparado com um banco de dados de composição química de aços, feita então a classificação do material utilizado na fabricação do pino esférico. A Tabela 5 apresenta o resultado da avaliação. $O$ material avaliado foi classificado como uma liga SAE 5140.

Tabela 5 - Resultados obtidos no ensaio de análise química

\begin{tabular}{|c|c|c|c|}
\hline Característica & $\begin{array}{c}\text { Método de } \\
\text { Verificação }\end{array}$ & $\begin{array}{c}\text { Critério de Aceitação } \\
\text { Item 6.1.1 }\end{array}$ & $\begin{array}{c}\text { Resultado } \\
\text { Obtido }\end{array}$ \\
\hline & & Conforme requisitos da ABNT & \\
Composição & NBR NM 87, com as seguintes \\
Química & Espectrofotometria & $\begin{array}{c}\text { exceções: Não serão aceitos aços- } \\
\text { carbono e aços ressulfurados para } \\
\text { Pinos beneficiados e temperados } \\
\text { por indução }\end{array}$ & $\begin{array}{c}\text { Atende a } \\
\text { Norma }\end{array}$ \\
& & $\begin{array}{c}\text { porado } \\
\end{array}$ &
\end{tabular}

A avaliação da conformidade do material via metalografia foi realizado após preparação metalográfica com lixamento até grana 120 Mesh e polimento com alumina $1 \mu \mathrm{m}$. O ataque químico para revelar a microestrutura foi realizado com Nital a $10 \%$.

A micrografia realizada junto à superfície mostra uma microestrutura típica de um aço temperado e revenido composta por uma matriz martensítica revenida, conforme ABNT NBR NM 136. Não foi evidenciada a presença de descarbonetação, conforme ABNT NBR 11299. A Figura 4 ilustra a microestrutura obtida. A Figura 5 mostra a região da rosca do pino esférico evidenciando que não houve arrancamento de material por usinagem. A Tabela 6 apresenta o resultado da avaliação. 


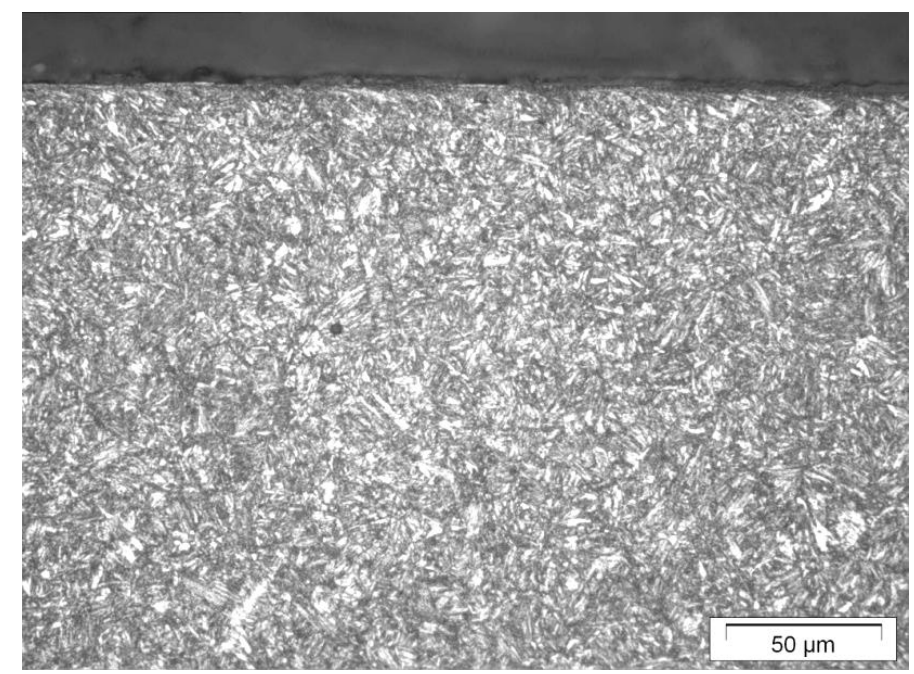

Figura 4 - Microestrutura martensítica obtida no pino esférico.

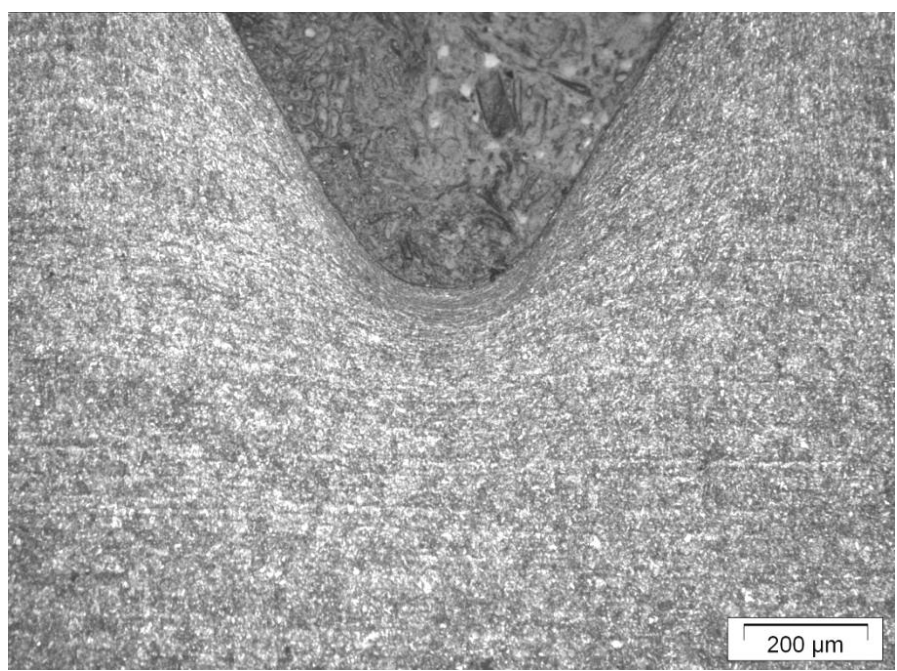

Figura 5 - Região da rosca do pino esférico. A superfície mostra um leve encruamento na raiz do filete, indicando possivelmente que os filetes foram obtidos através de conformação mecânica "não formada por remoção de material".

Tabela 6 - Resultados obtidos no ensaio.

\begin{tabular}{|c|c|c|c|}
\hline Característica & $\begin{array}{c}\text { Método de } \\
\text { Avaliação }\end{array}$ & $\begin{array}{c}\text { Critério de Aceitação } \\
\text { Item 6.1.4.1 }\end{array}$ & Laudo \\
\cline { 1 - 2 } Estrutura metalográfica & \multirow{2}{*}{ Metalografia } & $\begin{array}{c}\text { Conforme ABNT 11568 } \\
\text { Martensita Revenida } \\
\text { Conforme ABNT NBR }\end{array}$ & \\
\cline { 1 - 1 } $\begin{array}{c}\text { Descarbonetação Superficial } \\
\text { total }\end{array}$ & & Atende a \\
\cline { 3 - 3 } & & Conforme ABNT 11299 & \\
\hline
\end{tabular}




\section{2 - Ensaio de torque de rotação do pino esférico do conjunto terminal de direção}

Nesse ensaio avalia-se a resistência à rotação do pino esférico em seu alojamento da carcaça do terminal de direção e o resultado serve como base para avaliação da conformidade da montagem e projeto do produto avaliado.

Antes do ensaio o terminal foi mantido à uma temperatura de $23^{\circ} \mathrm{C} \pm 5^{\circ} \mathrm{C}$ e disposto em um dispositivo de torção rigidamente fixado. A coifa de proteção foi removida e a célula de torque do equipamento foi ajustada adequadamente à carcaça e pino esférico. A Figura 6 apresenta o esquema da montagem do ensaio de torque de rotação.

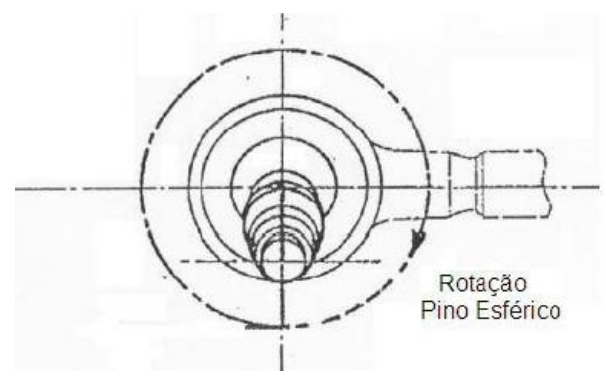

Figura 6 - Ilustração do esquema de montagem do ensaio de torção do pino esférico do terminal de direção [1].

Foi imposto um movimento rotacional no sentido horário, com velocidade angular constante de $5 \pm 0,5 \mathrm{rpm}$ e a temperatura durante o ensaio foi mantida em $24^{\circ} \mathrm{C}$. O valor de torque foi registrado durante a execução do ensaio, após o pino ter realizado cinco rotações completas. $\mathrm{O}$ valor de torque inicial foi registrado imediatamente à primeira movimentação do pino esférico. A Tabela 7 apresenta os resultados do ensaio de torção.

Tabela 7 - Resultados obtidos no ensaio de rotação do pino esférico.

\begin{tabular}{|c|c|c|c|c|}
\hline Amostra & $\begin{array}{c}\text { Diâmetro do } \\
\text { Pino Esférico } \\
\text { (mm) }\end{array}$ & $\begin{array}{c}\text { Torque Inicial } \\
\text { máximo após 24h } \\
\text { em repouso (Nm) }\end{array}$ & $\begin{array}{c}\text { Torque Máximo após } \\
\text { 5 rotações completas } \\
\text { (Nm) }\end{array}$ & Resultado \\
\hline $\begin{array}{c}\text { Critério de } \\
\text { Aprovação } \\
\text { Item 6.3.1 }\end{array}$ & $29 \leq \varnothing \leq 35$ & 30 & 18 & - \\
\hline $\begin{array}{c}\text { Amostra } \\
\text { avaliada }\end{array}$ & 30 & 4,20 & 4,43 & $\begin{array}{c}\text { Atende à } \\
\text { norma }\end{array}$ \\
\hline
\end{tabular}

\section{3 - Resistência ao arrancamento do pino esférico do conjunto terminal de direção}

O ensaio de arrancamento do pino esférico do componente carcaça avalia a força máxima que o pino esférico resiste antes da soltura total do item. A força mínima especificada pela norma representa a condição mais crítica de utilização do item.

Para o ensaio o componente é fixamente rígido em um dispositivo acoplado à uma máquina universal de ensaios. A coifa de proteção foi removida e a célula de carga do equipamento foi ajustada adequadamente à rosca do pino esférico. Deve-se garantir que não haja folgas no sistema de fixação e que o suporte de apoio da carcaça não influencie nos resultados obtido no 
ensaio. A Figura 7 apresenta o esquema da montagem do ensaio de arrancamento com indicação do sentido de aplicação das forças de tração e compressão aplicada (P1 e P2) que induz a separação entre o pino esférico e a carcaça.

A velocidade do ensaio foi de $1 \mathrm{~mm} / \mathrm{min}$, com temperatura ambiente de $24^{\circ} \mathrm{C}$. O ensaio foi realizado em uma Máquina Universal de Ensaio Emic DL 60000. A Figura 8 ilustra a montagem durante o ensaio de arrancamento do pino esférico do conjunto terminal de direção. A Tabela 8 apresenta os resultados obtidos no ensaio.

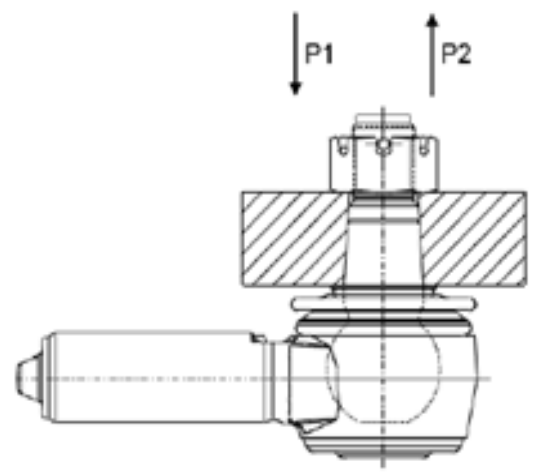

Figura 7 - Esquema da montagem do ensaio de arrancamento.

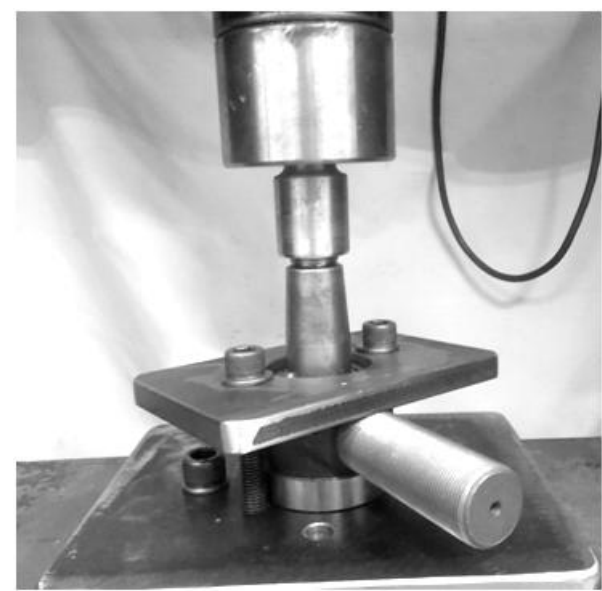

Figura 8 - Montagem durante o ensaio de arrancamento do pino esférico do conjunto terminal de direção.

Tabela 8 - Resultados obtidos no ensaio.

\begin{tabular}{|c|c|c|c|c|}
\hline Amostra & $\begin{array}{c}\text { Diâmetro do } \\
\text { Pino Esférico } \\
(\mathbf{m m})\end{array}$ & $\begin{array}{c}\text { Força de Tração } \\
(\mathbf{P 1}) \text { mín. }(\mathbf{k N})\end{array}$ & $\begin{array}{c}\text { Força de } \\
\text { Compressão (P2) } \\
\text { mín. (kN) }\end{array}$ & Resultado \\
\hline $\begin{array}{c}\text { Critério de } \\
\text { Aprovação } \\
\text { Item 6.3.3 }\end{array}$ & $29 \leq \emptyset<34$ & 80 & 30 & - \\
\hline $\begin{array}{c}\text { Amostra } \\
\text { Avaliada }\end{array}$ & 30 & $\begin{array}{c}\text { Obtido 88KN } \\
\text { Sem Rompimento }\end{array}$ & $\begin{array}{c}\text { Obtido 33KN } \\
\text { Sem Rompimento }\end{array}$ & $\begin{array}{c}\text { Atende à } \\
\text { norma }\end{array}$ \\
\hline
\end{tabular}




\section{4 - Elasticidade do pino esférico sob carga do conjunto terminal de direção}

$\mathrm{Na}$ avaliação da elasticidade do pino esférico sob carga do conjunto terminal de direção, as folgas de axiais e radiais são avaliadas sob aplicação de um carregamento estático. O ensaio realizado em um dispositivo adequado em uma máquina universal de ensaios serve como base para a avaliação da conformidade do produto e eventuais desvios do processo produtivo. A folga máxima sob carga especificada pela norma representa a condição mais crítica de utilização do item.

Para o ensaio o componente é fixamente rígido em um dispositivo acoplado à uma máquina universal de ensaios. A coifa de proteção foi removida e a célula de carga do equipamento foi ajustada adequadamente à rosca do pino esférico. Deve-se garantir que não haja folgas no sistema de fixação e que o suporte de apoio da carcaça não influencie nos resultados obtidos no ensaio. A Figura 9 apresenta o esquema da montagem do ensaio com indicação do sentido de aplicação das forças de tração e compressão aplicada (F e F1), respectivamente para avaliação da folga axial e radial.

A velocidade do ensaio foi de $0,5 \mathrm{~mm} / \mathrm{min}$, com temperatura ambiente de $24^{\circ} \mathrm{C}$. O ensaio foi realizado em uma Máquina Universal de Ensaio Emic DL 60000. A Tabela 9 apresenta os resultados obtidos no ensaio.

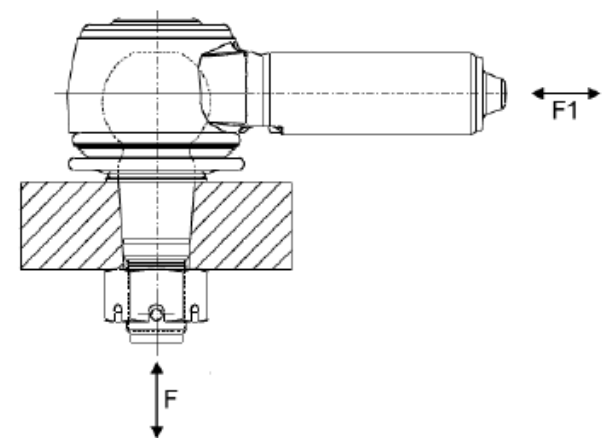

Figura 9 - Ilustração da montagem do ensaio de elasticidade do pino esférico

Tabela 9 - Resultados obtidos no ensaio.

\begin{tabular}{|c|c|c|c|c|}
\hline Amostra & $\begin{array}{c}\text { Diâmetro do } \\
\text { Pino Esférico } \\
(\mathbf{m m})\end{array}$ & $\begin{array}{c}\text { Deslocamento } \\
\text { Axial (F) (mm/N) }\end{array}$ & $\begin{array}{c}\text { Deslocamento } \\
\text { Radial (F1) (mm/N) }\end{array}$ & Resultado \\
\hline $\begin{array}{c}\text { Critério de } \\
\text { Aprovação } \\
\text { Item 6.3.2 }\end{array}$ & $29 \leq \varnothing \leq 34$ & $\leq 0,4 / 750$ & $\leq 0,35 / 5000$ & - \\
\hline $\begin{array}{c}\text { Amostra } \\
\text { avaliada }\end{array}$ & 30 & $0,19 / 750$ & $0,35 / 5000$ & $\begin{array}{c}\text { Atende à } \\
\text { norma }\end{array}$ \\
\hline
\end{tabular}

\section{CONCLUSÃO}

O trabalho apresentou os resultados de um estudo de caso da avaliação de terminais e barras de direção. Os resultados apresentados resultados de algumas técnicas utilizadas na avaliação 
desses produtos representam parte de um estudo bem mais completo e mostram que o produto avaliado atende à norma ABNT NBR 16130 e à Portaria do Inmetro nº 247 de 2013.

\section{REFERÊNCIAS}

[1]. ASSOCIAÇÃO BRASILEIRA DE NORMAS TÉCNICAS. NBR 16130: 2012: veículos rodoviários automotores - terminais de direção, barras de direção, barras de ligação e conjuntos de barras axiais - requisitos e métodos de ensaio aplicados a veículos categorias $\mathrm{M}$ e N e categorias G e O (quando aplicável). Rio de Janeiro: ABNT, 2012. 16p.

[2]. INSTITUTO NACIONAL DE METROLOGIA, QUALIDADE E TECNOLOGIA. PORTARIA N. ${ }^{\circ}$ 247: regulamento técnico da qualidade para terminais de direção, barras de direção, barras de ligação e terminais axiais. Rio de Janeiro: INMETRO, 03 de maio de 2013. $16 \mathrm{p}$. 